\title{
Program for Promoting the Employment of Schizophrenic Patients in Japan
}

\author{
Hatsumi Yoshii ${ }^{1} \&$ Nobutaka Kitamura ${ }^{2}$ \\ ${ }^{1}$ Health Sciences, Tohoku University, Graduate School of Medicine, Miyagi, Japan \\ ${ }^{2}$ Niigata University Graduate School of Medicine, Japan \\ Correspondence: Hatsumi Yoshii, Health Sciences, Tohoku University, Graduate School of Medicine, 2-1 \\ Seiryo-machi, Aoba-ku, Sendai, Miyagi, 980-8575 Japan. Tel: 81-22-717-7954. E-mail: \\ hatsumi@med.tohoku.ac.jp
}

Received: January 27, 2018 Accepted: February 20, 2018 Online Published: April 4, 2018

doi:10.5539/gjhs.v10n5p70 URL: https://doi.org/10.5539/gjhs.v10n5p70

\begin{abstract}
In Japan, a large proportion of schizophrenic patients cannot find work. Accordingly, it is necessary to promote positive attitudes among employers about hiring such patients. However, few programs in Japan educate employers about schizophrenia and there is little evaluation of such programs. Our study participants were 1,175 executives in private enterprises who registered with an Internet questionnaire survey company. The participants in the intervention group viewed an educational video developed to increase understanding about schizophrenia. This longitudinal study examined how employers' attitudes about hiring schizophrenic patients changed before and after watching the video. The number of respondents from both the intervention and non-intervention groups who responded that they did not understand how to employ and manage schizophrenics and so would not hire them showed a significant increase at 1 week after baseline $(p=0.001)$; however, there was a significant increase at 3 years after baseline only in the non-intervention group $(p=0.019)$. Only in the non-intervention group did Social Distance Scale-Japanese version scores show a significant decrease at 1 week after baseline $(p=0.011)$; they increased significantly from 1 week after to 3 years after baseline $(p=0.001)$. Our educational intervention aimed to promote employers' willingness to employ schizophrenic patients. However, to reduce stigma and increase such willingness, our program could be improved.
\end{abstract}

Keywords: schizophrenia, employment, knowledge, stigma, education program

\section{Introduction}

There are expectations of an ongoing decline in the birthrate and rise in the proportion of older citizens in Japan; that trend will lead to a society characterized by depopulation (Cabinet Office, Government of Japan, 2017). The working population is also likely to decrease, which will have a consequential negative influence on economic growth (Ministry of Internal Affairs and Communications, 2017). To address these issues, measures are being undertaken to promote the employment of individuals with physical and mental disorders.

The employment of people with mental disorders in Japan has shown some progress. In June 2013, a revised government act was promulgated: it covered mental disorders as a basis for calculating the legal employment rate. As a result of this action, it is expected that more people with mental disorders will be hired in the future. However, the relatively low rate of employment of individuals with mental disorders in Japan is conspicuous. As of June 2013, among private enterprises employing $>50$ workers, there were 22,000 individuals with mental disorders; that compares with 303,000 people with physical disorders and 82,000 with intellectual disabilities.

At the societal level, it would be desirable for people with mental disorders to raise their productivity in the labor market. That development could increase the incomes of enterprises and workers; it could reduce the social security expenses (such as livelihood protection) of taxpayers. However, schizophrenic patients are often eager to work but have difficulty joining the labor market (Japan Organization for Employment of the Elderly, Persons with Disabilities and Job Seekers, 2017; National Institute of Vocational Rehabilitation, 2010).

To increase the employment of individuals with schizophrenia, it is necessary to help employers understand the condition more completely. To that end, we developed an educational program to promote greater knowledge about schizophrenia and reduce the associated stigma. We tested the effectiveness of this program among 
employers. Our aim was to use the results to develop strategies for promoting employment and helping schizophrenic patients join the job market.

\section{Methods}

\subsection{Subjects}

First, we undertook a screening investigation to extract participants aged 20 years and over among private companies identified by a Japanese survey company. Second, we used gender, region, and company size as variables to stratify random sampling. Participants completed a questionnaire about their demographic characteristics, living environment, views about schizophrenia, employment, and previous testing. The subjects in the intervention group participated in the schizophrenia employment-promotion program we developed.

The interval between the pre-test and post-test was 1 week. The final test was conducted after 3 years.

The present study was consistent with the principles outlined in the Helsinki declaration for the ethical conduct of human research. This investigation was approved by the medical ethics committee of Tohoku University. Informed (Web-based) consent was obtained from all participants prior to participation.

\subsection{Ethical Considerations}

The participants were informed that the content of the investigation would be used only for research. They were told that their participation would remain confidential and that all data would be handled anonymously.

\subsection{Measures}

The questionnaire used in this study comprised seven scales. Scale 1 collected the respondents' demographic data. Scale 2 comprised items on basic knowledge of schizophrenia (BKS). Higher scores signify greater knowledge.

Scale 3 examined knowledge about mental disorders according to the Knowledge of Illness and Drugs Inventory (KIDI) scale (Cronbach's $\alpha=0.69$ ) (Maeda, Ochiai, Renri, Aga, \& Mukasa, 1994). Higher scores indicate greater knowledge.

Scale 4 examined social distance toward schizophrenia according to the Social Distance Scale-Japanese version (SDSJ) (Cronbach's $\alpha=0.849$ ) (Whatley, 1959). Higher scores represent greater social distance.

Scale 5 examined social distance toward mental disorder in the workplace according to the Workplace Social Distance Scale (WSDS) (Cronbach's $\alpha=0.753$ ) (Yoshii, Mandai, Saito, \& Akazawa, 2015). Higher scores denote greater social distance.

Scale 6 examined stigma toward mental disorder according to the Devaluation-Discrimination Measure (DDM) (Cronbach's $\alpha=0.85$ ) (Link, 1987). Higher scores indicate greater stigma.

Scale 7 covered mental disease and employment. The items included employment experience with schizophrenia and employment hopes, e.g.; "Would you be willing to hire a person with a mental illness who is undergoing medication?"

The respondents gave their questionnaire answers about scales 2-7 at three time points before and after watching the education video: at baseline; 1 week after baseline; and 3 years after baseline.

\subsection{Education Video: Intervention for Intervention Group}

After the baseline test, the intervention group was invited to view a Web-based education video developed to increase knowledge as well as enhance positive employment attitudes toward schizophrenics. The video covered 15 units: characteristics of schizophrenia; its causes; its symptoms; classification of schizophrenia; disease course and characteristic clinical features; schizophrenia treatment; prognosis; employment considerations; signs of progression; consultation facilities; legal issues; cooperative organizations; support systems; report of employment experience; and case reports. The video consisted of a slide show with 24 narrated slides (duration, 30 minutes). It was possible to view the video slide show on the same Internet Web site as that for the questionnaire in the intervention group. All participants evaluated the program's effectiveness after 1 week and after 3 years.

\subsection{Analytic Methods}

We performed all analyses using SPSS Statistics for Windows, version 20.0. For the employment of schizophrenic patients, we used McNemar's chi-square test to compare the proportion of specific answers among paired data (i.e., for the results of the baseline and post-test questionnaires). We utilized that test to compare the intervention and non-intervention groups.

We employed analysis of variation and multiple comparisons to compare the means \pm standard deviations of 
specific answers about questions of knowledge and attitudes related to schizophrenia in the paired data from the questionnaires at baseline, after 1 week, and after 3 years. We used the Student $t$ test to compare the intervention and non-intervention groups. All statistical tests were two-tailed; statistical significance was defined as $p<0.05$.

\section{Results}

\subsection{Participant Characteristics}

There were 1,175 respondents (1,109 men, 66 women): 120 were in their $30 \mathrm{~s} ; 444$ in their $40 \mathrm{~s} ; 467$ in their $50 \mathrm{~s}$; and 144 in their 60s or over. Regarding highest level of educational attainment, the participants had completed the following: 107, graduate school; 713, college; 37, junior college; 108, vocational school; 203, high school; 5, junior high school; and 2, other. Employment by sector was as follows: 5 participants, agriculture, forestry, and fisheries; 289, manufacturing; 14, electric utility; 80, medical care; 44, transportation; 143, retail trade; 53, professional employment; and 547, other.

\subsection{Effect of Education Video}

\subsubsection{Change in Employment Attitudes after Viewing the Video}

At baseline, many participants were undecided about hiring schizophrenic patients: intervention group, 52.8\%; non-intervention group, 49.6\% (Table 1). Few participants were positive about the benefits of such employment: intervention group, 2.6\%; non-intervention group, $2.8 \%$. We administered the same questionnaire to all the participants after the intervention group had watched the education video. In both the intervention and non-intervention groups, the number of participants who responded that they would make positive efforts to employ schizophrenics showed a significant increase at 3 years after baseline: intervention group, $p=0.001$; non-intervention group, $p=0.002$. In both the intervention and non-intervention groups, the number of participants who responded that they would not make positive efforts to employ schizophrenics, but might employ them if someone moderately competent applied, showed a significant increase between 1 week after baseline and 3 years after baseline $(p=0.001)$. In both the intervention and non-intervention groups, respondents who answered that they would not understand how to employ and manage schizophrenics and so would not hire them showed a significant increase at 1 week after baseline $(p=0.001)$; it increased significantly at 3 years after baseline only in the non-intervention group $(p=0.019)$. Furthermore, the number of participants who responded that they thought schizophrenics would be incompetent and would have a hard time adapting to the workplace and so would not hire them decreased significantly at 3 years after baseline only for the non-intervention group $(p=0.008)$.

\subsubsection{Change in Knowledge and Attitudes}

We observed significant differences in the three group comparisons (at baseline, after 1 week, and after 3 years) for KIDI, WSDS, DDM, and SDSJ in both the intervention and non-intervention groups ( $p=0.005$ to 0.001 ; Table 2). In both the intervention and non-intervention groups, KIDI increased significantly at 1 week after baseline; it decreased significantly from 1 week to 3 years after baseline $(p=0.001)$. In both the intervention and non-intervention groups, WSDS decreased significantly at 1 week after baseline (intervention group, $p=0.037$; non-intervention group, $p=0.002$ ); it increased significantly from 1 week to 3 years after baseline (intervention, $p$ $=0.01$; non-intervention, $p=0.001$ ). In addition, DDM decreased significantly at 3 years after baseline in both the intervention and non-intervention groups ( $p=0.001$ and $p=0.002$, respectively); it decreased significantly from 1 week to 3 years after baseline $(p=0.001)$. SDSJ decreased significantly only in the non-intervention group at 1 week after baseline $(p=0.011)$; it increased significantly from 1 week to 3 years after baseline $(p=0.001)$.

\section{Discussion}

\subsection{Employment of Schizophrenic Patients}

Regarding handicapped workers, assistance in Japan for employers is provided mainly by the Japan Organization for Employment of the Elderly, Persons with Disabilities and Job Seekers. Such support includes the following: (1) consultation with employers concerning various employment-related issues and drawing up an employer support plan; (2) dispatching job coaches to workplaces and providing professional assistance for handicapped people and their employers; (3) employment management (support services for medical care, improvement of facilities and instruments at workplaces, improvement of working conditions); (4) providing grants to employers who hire handicapped individuals; and (5) events and educational activities about employing handicapped people (Japan Organization for Employment of the Elderly, Persons with Disabilities and Job Seekers, 2017). However, these support activities are provided only if employers are willing to hire handicapped workers: if employers are not so inclined, they will not apply for these support services in hiring mentally handicapped individuals.

Previous research has examined support programs for employers that included job-placement services for 
schizophrenic patients (Crain et al., 2009) and supported employment systems for severely mentally handicapped people (Perkins, Born, Raines, \& Galka, 2005). However, no decisive conclusions have been reached about the effectiveness of such interventions - even though a program to encourage understanding of mentally handicapped individuals among employers has been implemented by the Employment Services at Maine Medical Center in the United States (Balser, Hagner, \& Hornby, 2000).

The present investigation was an intervention study with the focus on encouraging employers to hire schizophrenic patients. Our education video can be viewed in just 30 minutes: it explains the merits of hiring schizophrenic patients and presents case studies. The intention with this educational intervention was to raise employers' willingness to hire schizophrenic patients. Relatively few participants were positive about the benefits of such employment: intervention group, 2.6\%; non-intervention group, $2.8 \%$ (Table 1). Furthermore, the number of respondents who stated that they did not understand how to employ and manage schizophrenics and so would not hire them showed a significant increase at 3 years after baseline only in the non-intervention group $(p=0.019)$. These results indicate that employment awareness worsened because education was not provided. Accordingly, the intervention employed in this study was effective; long-term observation was necessary to determine those changes in the employers' viewpoints. Having demonstrated the efficacy of this video, we would like to enhance this approach and help improve the employment rates of schizophrenic patients.

\subsection{Attitudes toward Schizophrenia}

In addition to assessing attitudes toward schizophrenia, reducing stigma among employers about that condition was one of the purposes of our video. In a number of surveys, employers have expressed negative attitudes about employing individuals with mental disorders (Diksa \& Rogers, 1996; Manning \& White, 1995). Various scales to measure these characteristics have been developed and used worldwide (Schulze, Richter-Werling, Matschinger, \& Angermeyer, 2003). In the present study, we employed three of these scales: SDSJ, WSDS, and DDM. In our study, DDM showed a significant decrease at 3 years after baseline in both the intervention and non-intervention groups; it displayed a significant decrease from 1 week to 3 years after baseline (Table 2). This indicates that presenting information about schizophrenia does not always lead to stigma reduction. According to one study on anti-stigma education, low education and a more negative attitude toward mental disorder offered greater potential for improvement following a similar kind of program (Gaebel et al., 2008). Analogous results have been reported elsewhere (Kvaale, Haslam, \& Gottdiener, 2013; Kvaale, Gottdiener, \& Haslam, 2013; Read, Haslam, Sayce, \& Davies, 2006). In the present study, in the non-intervention group, the SDSJ scores showed a significant decrease at 1 week after baseline but a significant increase from 1 week to 3 years after baseline. These results suggest that long-term social distance worsened through lack of education. Thus, the intervention investigated in this study was effective; long-term observation was necessary to assess attitudinal changes.

Various educational programs have addressed a range of stigma issues. For example, the Mental Health First Aid (MHFA) training course (a standardized 12-hour training program) (Lam, Jorm, \& Wong, 2010) for general members of the Chinese community in Melbourne produced a significant positive change in the level of mental health literacy; it also reduced stigmatizing attitudes (See Me Scotland). The Training and Education about Mental Illness for Police Organizations (TEMPO) model is a multilevel learning strategy for Canadian police personnel (Coleman \& Cotton, 2014); it comprises anti-stigma education to challenge the attitudinal barriers that lead to discriminatory action: "In addition to providing a firm basis of factual knowledge for police personnel, the resultant model embraces a human rights/anti-stigma philosophy, provides for a range of education appropriate to diverse police audiences, emphasizes a systems approach to police/mental health liaison activities and addresses issues related to the delivery and implementation of police education and training" (Coleman \& Cotton, 2014). These educational programs (MHFA training course and TEMPO) use participatory approaches, and trained coaches are responsible for implementing the programs.

It may be necessary to reexamine the effects of our program and apply a participatory method. According to statistics from the Japanese Ministry of Health, Labour and Welfare (Lam et al., 2010), the employment rate for people with mental disorders is significantly lower than that for individuals with physical disorders: $0.7 \%$ and $19.3 \%$, respectively. Therefore, opportunities for contact with mental disorder in the workplace are likely to be very limited in Japan. To make our program as participatory as possible, it may be useful to change our present method (viewing illustrations on slides showing working experiences of schizophrenic patients and employers' hiring experiences). Instead, it may be better to use live-action videos, showing patients and employers in the workplace. 
Table 1. Change in employment attitudes after viewing video $(\mathrm{n}=1,175)$

\begin{tabular}{|c|c|c|c|c|c|c|c|c|c|c|c|c|c|}
\hline & \multicolumn{5}{|c|}{ Intervention group $(n=610)$} & \multicolumn{5}{|c|}{ Non-intervention group $(n=565)$} & \multicolumn{3}{|c|}{$\begin{array}{l}\text { Intervention group vs. } \\
\text { non-intervention group }\end{array}$} \\
\hline & Baseline & 1 week & 3 years & $\begin{array}{l}\text { Baseline } \\
\text { vs. } \\
1 \text { week }\end{array}$ & $\begin{array}{l}\text { Baseline } \\
\text { vs. } \\
3 \text { years }\end{array}$ & Baseline & 1 week & 3 years & $\begin{array}{l}\text { Baseline } \\
\text { vs. } \\
1 \text { week }\end{array}$ & $\begin{array}{l}\text { Baseline } \\
\text { vs. } \\
3 \text { years }\end{array}$ & Baseline & $\begin{array}{l}1 \\
\text { week }\end{array}$ & $\begin{array}{l}3 \\
\text { years }\end{array}$ \\
\hline & \multicolumn{3}{|c|}{ n (\%) } & \multicolumn{2}{|c|}{$P 1$} & \multicolumn{3}{|c|}{ n (\%) } & \multicolumn{2}{|c|}{$P 1$} & \multicolumn{3}{|c|}{$P 2$} \\
\hline $\begin{array}{l}\text { I want to make positive efforts to } \\
\text { employ schizophrenics }\end{array}$ & $16(2.6)$ & $29(4.8)$ & $41(6.7)$ & 0.061 & $0.001 *$ & $16(2.8)$ & $19(3.4)$ & $40(7.1)$ & 0.710 & $0.002 *$ & 0.826 & 0.229 & 0.809 \\
\hline $\begin{array}{l}\text { I do not want to make positive } \\
\text { efforts to employ schizophrenics, } \\
\text { but I may employ them if someone } \\
\text { moderately competent applies }\end{array}$ & $105(17.2)$ & $208(34.1)$ & $180(29.5)$ & $0.001 *$ & $0.001 *$ & $112(19.8)$ & $186(32.9)$ & $176(31.2)$ & $0.001 *$ & $0.001 *$ & 0.249 & 0.669 & 0.541 \\
\hline $\begin{array}{l}\text { I do not understand how to employ } \\
\text { and manage schizophrenics, so I } \\
\text { would not hire them }\end{array}$ & $69(11.3)$ & $107(17.5)$ & $76(12.5)$ & $0.001 *$ & 0.569 & $51(9.0)$ & $89(15.8)$ & $75(13.3)$ & $0.001 *$ & $0.019 *$ & 0.196 & 0.411 & 0.676 \\
\hline $\begin{array}{l}\text { I think schizophrenics will be } \\
\text { incompetent and will have difficulty } \\
\text { in adapting to the workplace, so I } \\
\text { will not employ them }\end{array}$ & $59(9.7)$ & $53(8.7)$ & $59(9.7)$ & 0.581 & 1.000 & $65(11.5)$ & $56(9.9)$ & $29(6.9)$ & 0.412 & $0.008^{*}$ & 0.307 & 0.470 & 0.086 \\
\hline $\begin{array}{l}\text { I have employed a schizophrenic } \\
\text { person in the past, but they were } \\
\text { incompetent or had difficulty in } \\
\text { adapting to the workplace, so I will } \\
\text { not hire another }\end{array}$ & $21(3.4)$ & $25(4.1)$ & $35(5.7)$ & 0.643 & 0.061 & $23(4.1)$ & $17(3.0)$ & $31(5.5)$ & 0.391 & 0.332 & 0.571 & 0.315 & 0.852 \\
\hline Other & $18(3.0)$ & $6(1.0)$ & $4(0.7)$ & $0.017 *$ & $0.003 *$ & $18(3.2)$ & $5(0.9)$ & $2(0.3)$ & $0.004 *$ & $0.001 *$ & 0.815 & 0.861 & 0.468 \\
\hline Undecided & $322(52.8)$ & $182(29.8)$ & $215(35.2)$ & $0.001 *$ & $0.001 *$ & $280(49.6)$ & $193(34.1)$ & $202(35.7)$ & $0.001 *$ & $0.001 *$ & 0.269 & 0.112 & 0.856 \\
\hline
\end{tabular}

$P 1$, difference between the baseline and after the indicated period, McNemar's test; $P 2$, difference within the groups, chi-square test, ${ }^{*} p<0.05$ 
Table 2. Change in knowledge, attitudes, and rating schizophrenic patients

\begin{tabular}{|c|c|c|c|c|c|c|c|c|c|c|c|c|c|c|c|c|c|}
\hline & \multicolumn{7}{|c|}{ Intervention group } & \multicolumn{7}{|c|}{ Non-intervention group } & \multicolumn{3}{|c|}{$\begin{array}{l}\text { Intervention group vs. } \\
\underline{\text { non-intervention group }}\end{array}$} \\
\hline & Baseline & 1 week & 3 years & $\begin{array}{l}\text { 3-group } \\
\text { comparison }\end{array}$ & $\begin{array}{l}\text { Baseline } \\
\text { vs. } \\
1 \text { week }\end{array}$ & $\begin{array}{l}\text { Baseline } \\
\text { vs. } \\
3 \text { years }\end{array}$ & $\begin{array}{l}1 \text { week } \\
\text { vs. } \\
3 \text { years }\end{array}$ & Baseline & 1 week & 3 years & $\begin{array}{l}\text { 3-group } \\
\text { comparison }\end{array}$ & $\begin{array}{l}\text { Baseline } \\
\text { vs. } \\
1 \text { week }\end{array}$ & $\begin{array}{l}\text { Baseline } \\
\text { vs. } \\
3 \text { years }\end{array}$ & $\begin{array}{l}1 \text { week } \\
\text { vs. } \\
3 \text { years }\end{array}$ & Baseline & $\begin{array}{l}1 \\
\text { week }\end{array}$ & $\begin{array}{l}3 \\
\text { years }\end{array}$ \\
\hline & & Mean \pm SD & & $P 1$ & $P 2$ & $P 2$ & $P 2$ & & Mean \pm SD & & $P 1$ & $P 2$ & $P 2$ & $P 2$ & $P 3$ & $P 3$ & $P 3$ \\
\hline BKS & $10.15 \pm 1.34$ & $10.36 \pm 1.32$ & $10.14 \pm 1.26$ & 0.249 & $0.003 *$ & 1.000 & $0.002 *$ & $10.18 \pm 1.23$ & $10.29 \pm 1.26$ & $10.18 \pm 1.19$ & 0.822 & 0.250 & 1.000 & 0.298 & 0.780 & 0.321 & 0.630 \\
\hline KIDI & $13.21 \pm 3.29$ & $14.10 \pm 3.19$ & $13.31 \pm 3.39$ & $0.001^{*}$ & $0.001^{*}$ & 1.000 & $0.001 *$ & $13.20 \pm 3.20$ & $13.96 \pm 3.06$ & $13.15 \pm 3.48$ & $0.001^{*}$ & $0.001 *$ & 1.000 & $0.001 *$ & 0.950 & 0.439 & 0.430 \\
\hline WSDS & $20.89 \pm 4.02$ & $20.56 \pm 4.05$ & $20.98 \pm 3.90$ & $0.005^{*}$ & $0.037^{*}$ & 1.000 & $0.010^{*}$ & $20.92 \pm 3.77$ & $20.49 \pm 3.88$ & $21.17 \pm 3.73$ & $0.001 *$ & $0.002 *$ & 0.346 & $0.001^{*}$ & 0.880 & 0.774 & 0.420 \\
\hline DDM & $31.58 \pm 4.46$ & $31.56 \pm 4.06$ & $30.55 \pm 4.20$ & $0.001^{*}$ & 1.000 & $0.001 *$ & $0.001 *$ & $31.47 \pm 4.14$ & $31.80 \pm 4.60$ & $30.84 \pm 4.01$ & $0.001^{*}$ & 0.106 & $0.002 *$ & $0.001 *$ & 0.660 & 0.34 & 0.220 \\
\hline SDSJ & $20.26 \pm 4.01$ & $20.19 \pm 4.11$ & $20.52 \pm 4.18$ & $0.001 *$ & 1.000 & 0.295 & 0.104 & $20.21 \pm 3.85$ & $19.84 \pm 4.07$ & $20.56 \pm 3.99$ & $0.001 *$ & $0.011^{*}$ & 0.081 & $0.001 *$ & 0.840 & 0.143 & 0.860 \\
\hline
\end{tabular}

Note: BKS = Basic Knowledge of Schizophrenia Scale; KIDI = Knowledge of Illness and Drugs Inventory; WSDS = Whatley Social Distance Scale; DDM = Devaluation-Discrimination Measure; SDSJ = Social

Distance Scale-Japanese version; $\boldsymbol{P} 1=$ difference within the groups, analysis of variance; $\boldsymbol{P} 2=$ difference between the groups, Bonferroni multiple comparison test; $\boldsymbol{P} 3=t$ test

$* p<0.05$ 


\section{Conclusion}

The educational intervention of our program aimed to promote employers' willingness to hire schizophrenic patients. Our findings suggest that the program should be improved to reduce stigma and increase that willingness.

\section{Acknowledgements}

The authors thank the study participants. This work was supported by the 2017 Health Science Center Foundation on Ethics and Education grant entitled "Education program on the employment of schizophrenic patients by employers."

\section{Competing Interests Statement}

The authors declare that they has no competing or potential conflicts of interest.

\section{References}

Balser, R. M., Hagner, D., \& Hornby, H. (2000). Partnership with the business community: The Mental Health Employer Consortium. Journal of Applied Rehabilitation Counseling, 31(4), 47-53.

Cabinet Office, Government of Japan. (2017). Retrieved from http://www.cao.go.jp/ (in Japanese)

Coleman, T. A., \& Cotton, D. (2014). TEMPO: A contemporary model for police education and training about mental illness. International Journal of Law and Psychiatry, 37, 325-333. https://doi.org/10.1016/j.ijlp.2014.02.002

Crain, M., Penhale, C., Newstead, C., Thomson, L., Heah, T., \& Barclay, K. (2009). The contribution of IPS to recovery from serious mental illness: A case study. Work, 33(4), 459-464. https://doi.org/10.3233/WOR-2009-0894.

Diksa, E., \& Rogers, E. S. (1996) Employer concerns about hiring persons with psychiatric disability: results of the Employer Attitude Questionnaire. Rehabilitation Counseling Bulletin, 40, 31-44.

Gaebel, W., Zaske, H., Baumann, A. E., Klosterkotter, J., Maier, W., Decker, P., \& Moller, H. J. (2008) Evaluation of the German WPA 'program against stigma and discrimination because of schizophrenia-Open the Doors': results from representative telephone surveys before and after three years of anti stigma interventions. Schizophrenia Research, 98, 184-193. https://doi.org/10.1016/j.schres.2007.09.013

Japan Organization for Employment of the Elderly, Persons with Disabilities and Job Seekers (JEED) (2017). Retrieved from http://www.jeed.or.jp/english/ (in Japanese)

Kvaale, E. P., Gottdiener, W. H., \& Haslam, N. (2013). Biogenetic explanations and stigma: a meta-analytic review of associations among laypeople. Social Science \& Medicine, 96, 95-103. https://doi.org/10.1016/j.socscimed.2013.07.017

Kvaale, E. P., Haslam, N., \& Gottdiener, W. H. (2013). The 'side effects' of medicalization: a meta-analytic review of how biogenetic explanations affect stigma. Clinical Psychology Review, 33, 782-794. https://doi.org/10.1016/j.cpr.2013.06.002

Lam, A. Y., Jorm, A. F., \& Wong, D. F. (2010). Mental health first aid training for the Chinese community in Melbourne, Australia: effects on knowledge about and attitudes toward people with mental illness. International Journal of Mental Health Systems, 4, 18. https://doi.org/10.1186/1752-4458-4-18

Link, B. G. (1987). Understanding labelling effects in the area of mental disorders: an assessment of the effects of expectations of rejection. American Sociological Review, 52, 96-112. https://doi.org/10.2307/2095395

Maeda, S., Ochiai, M., Renri, T., Aga, J., \& Mukasa, H. (1994). Research of the results of Knowledge of Illness and Drugs Inventory (KIDI) toward schizophrenia and the patients' family. Japanese Bulletin of Social Psychiatry, 2, 173 (in Japanese).

Manning, C., \& White, P. D. (1995) Attitudes of employers to the mentally ill. Psychiatric Bulletin, 19, 541-543. https://doi.org/10.1192/pb.19.9.541

Ministry of Internal Affairs and Communications. (2017). Retrieved from http://www.stat.go.jp/data/index.htm (in Japanese)

National Institute of Vocational Rehabilitation. (2010). Retrieved from http://www.nivr.jeed.or.jp/center/center.html (in Japanese)

Perkins, D. V., Born, D. L., Raines, J. A., \& Galka S. W. (2005) Program evaluation from an ecological perspective: Supported employment services for persons with serious psychiatric disabilities. Psychiatric Rehabilitation 
Journal, 28(3), 217-224. https://doi.org/10.2975/28.2005.217.224

Read, J., Haslam, N., Sayce, L., \& Davies, E. (2006) Prejudice and schizophrenia: a review of the 'mental illness

Schulze, B., Richter-Werling, M., Matschinger, H., \& Angermeyer, M. C. (2003). Crazy? So what! Effects of a school project on student's attitudes towards people with schizophrenia. Acta Psychiatrica Scandinavica, 107, 142-150. https://doi.org/10.1034/j.1600-0447.2003.02444.x

Whatley, C. (1959) Social attitudes towards discharge mental patients. Social Problems, 6, 313-320. https://doi.org/10.1525/sp.1959.6.4.03a00050

Yoshii, H., Mandai, N., Saito, H., \& Akazawa, K. (2015) Reliability and validity of the workplace social distance scale. Global Journal of Health Science, 7(3), 46-51. https://doi.org/10.5539/gjhs.v7n3p46

\section{Copyrights}

Copyright for this article is retained by the author(s), with first publication rights granted to the journal.

This is an open-access article distributed under the terms and conditions of the Creative Commons Attribution license (http://creativecommons.org/licenses/by/4.0/). 